\title{
Comparison between Pigment Printing Systems with Acrylate and Butadiene Based Binders
}

\author{
Mansoor Iqbal, Javaid Mughal, Munazza Sohail, Arsheen Moiz, Kamran Ahmed, Khalil Ahmed*
}

Applied Chemistry Research Centre, PCSIR Laboratories Complex, Karachi, Pakistan.

Email: *khalilmsrc@gmail.com

Received December $25^{\text {th }}, 2011$; revised January $16^{\text {th }}, 2012$; accepted January $31^{\text {st }}, 2012$

\begin{abstract}
Pigment printing was carried out on lab scale by simple screen-printing techniques. By the application of acrylate and butadiene based binder, the crocking fastness, formaldehyde release and PVC migration of fabric printed with Imparon red KB pigment was evaluated. The effect of curing time on K/S values was also investigated. It has been found that butadiene based binder shows good performance in terms of crocking fastness, formaldehyde release and PVC migration. It has also been observed that by increasing the binder concentration, the release of formaldehyde decreased and by increasing the curing time, the K/S values of printed fabric were decreased.
\end{abstract}

Keywords: Printing; Pigment; Binder; Acrylate; Butadiene

\section{Introduction}

Cotton is one of the most important fibers in the textile industry and its coloration could be achieved with either dyes, by dyeing or printing in aqueous solution, or with pigment by using a print paste. Printing of cellulosic fibers are considered to account for more than $70 \%$ of all printed substrates and pigment printing is a major method [1]. The use of pigments for printing of textile products has dramatically increased over the last 50 years. Pigments are now used to produce printed products for a number of end uses including apparels, home furnishing, crafts and nonwoven articles of the over 18 billion liners yards of printed fabric produced worldwide each years, about $50 \%$ of this yardage is pigment printed. In the united state alone, currently about $80 \%$ of all printing is done with pigment [2]. There are of course limitations to balance against the substantial advantages of pigment printing. The printer should be fully aware of these, since the use of pigments in applications where dyes are required can bring about a negative attitude to pigments, even in suitable applications [3]. In pigment printing, insoluble pigments, which have no affinity for fibers, are fixed on to the fibers with binding agents or binders [4]. Depending upon the properties required in the binding film (softness, elasticity, plasticity, solvent stability), binders can be tailor-made by choosing suitable base product. It is necessary to copolymerize different monomers. Typically, unsaturated monomers are used, such as

${ }^{*}$ Corresponding author. vinyl chloride, dichloroethene, acrylic acid, acrylonitrile, acrylic acid esters \& ethers. The binder used in the pigment printing process is usually based on styrene-butadiene, styrene acrylate or vinyl acetate-acrylate copolymer [5]. Binders are the mechanism used to keep the color on the fabric when using pigments for printing textiles. The choice of binders will always depend upon the final fastness requirements as well as the cost requirements of the process. Choosing a binder for pigment coloration is a complex but critical step in developing a recipe which will meet very specific requirements. The place to start to determine which final fabric properties are important as various end use applications may require a different polymer to achieve the desired results [6]. Almost all the binders used in textile pigment printing are the addition polymerization products. They are actually copolymer type; the structure may be represented as Figure 1 [7].

The binder film in pigment print is a three-dimensional structure, the third dimension is rather less important than the other two. The binder is a film-forming substance made up of long chain macromolecules, which when applied to the textile together with the pigment, produces a three-dimensionally network. The links are<smiles>CCOC(=O)C(CC(C)C)CC(CC(C)C)C(=O)OCC</smiles>

Figure 1. General structure of acrylate copolymer. 
formed during some suitable fixing process, which usually consists of dry heat and change in $\mathrm{pH}$ value, bringing about either self-crosslinking or reaction with other suitable crosslinking agents [8]. Elasticity and improved adhesion of the film to the substrate is achieved by crosslinking. The crosslinking reaction must produce covalent bonds, which are insensitive to hydrolyzing agents (washing liquor, perspiration, industrial atmosphere). The reaction should be activated in dry hot air by curing process [9]. While the prints are being dried, a film is formed from the dispersed binder. Its formation takes place in two stages: flocculation (or coagulation) and coalescence. During the first stage of film formation, water and surfactants are removed from the binder by

$$
\text { Binder- } \mathrm{CH}_{2} \text {-OR + HO-Cellulose }
$$

where $\mathrm{R}$ is $\mathrm{CH}_{3}$ or $\mathrm{H}$.

Cross linking increases the crocking, washing and dry cleaning fastness properties, but detrimentally affects the handle of the fabric. When the binder molecule have no self-crosslinking groups, an additional cross linking agent such as urea formaldehyde or melamine formaldehyde condensate, methylolated urethane compounds etc, having at least two reactive groups per molecule are added in the binder system [11].

The present research work demonstrates the comparisons between pigment printing systems with acrylate and butadiene based binders. The influence on the crocking fastness, PVC migration, formaldehyde release and K/S values of the printed cotton fabric has also been investigated.

\section{Experimental}

\subsection{Material}

An optical brightener free, $100 \%$ cotton woven fabric having construction 25 ends $/ \mathrm{cm}^{2}, 21$ picks $/ \mathrm{cm}^{2}$ and an area density of $142 \mathrm{gm} / \mathrm{m}^{2}$ was used for pigment printing purpose. The fabric was desized enzymatically, scoured and bleached by an exhaust method.

\subsection{Chemical \& Colorants}

Commercial pigment Imparon KB of BASF was used as a colorant in the printing process. Two different binder, binder ET (polyacrylate based) and halazarine binder FRS (butadiene based) of BASF were used. Leutexol HP was also supplied by BASF and used as a thickener. Printofix WB liquid (melamine based) used as a fixative. All other chemicals ammonia, urea, polyvinyl chloride, $\mathrm{TiO}_{2}$ were purchased from Merck chemicals Pakistan limited.

\subsection{Equipments}

Printing was carried out by laboratory hand screen-print- absorption and evaporation. The dispersed solids coagulate to form a gel-like layer of very tightly packed 'balls', which have only poor solidity and adhesive properties. If the mechanically more stable, more redispersible, dispersion binders are used, these coagulated particles can be brought back to their original form by rubbing them with water. During the second phase, the gel particles flow together to form a continuous film.

The lowest temperature at which a film can be formed depends upon chemical constitution, but for pigment printing it is usually around $5^{\circ} \mathrm{C}$. The speed at which the film is formed depends upon the range of particle size [10]. The reaction between the binders and the cellulosic substrate may be represented as follows in equation: ing. Samples were cured on curing machine of Rapid. Crocking fastness evaluated on AATCC Crock meter (CM-5 SDL Atlas), Fastness rating was evaluated on color matching cabinet of Verified by comparing with grey-scale. The viscosity of the thickener paste was determined by Brookfield viscometer (DV-E model) with spindle number 6.The relative color strength of the prints, expressed as K/S values L, a, b, c CIE lab of the printed samples were determined by reflectance measurements using Data color international spectrophotometer SF600.

\subsection{Print Paste Preparation}

The print paste was prepared in soft water with heavy string by adding $15 \mathrm{~g} / \mathrm{kg}$ acrylate and butadiene based binder separately, 12 - $14 \mathrm{~g} / \mathrm{kg}$ thickener, $6 \mathrm{~g} / \mathrm{kg}$ ammonia to attain a $\mathrm{pH} 8-9$ and $0.7 \%-0.8 \% \mathrm{w} / \mathrm{w}$ fixative were also added. Each print paste was prepared with 5\% Imparon KB pigment and 95\% stock paste. The viscosity of the final print paste was 28000 cps as determined with Brookfield viscometer.

\subsubsection{Print Method}

The printed fabric dried at $120^{\circ} \mathrm{C}$ for 2 min and cured at $155^{\circ} \mathrm{C}$ for 5 minutes.

\subsubsection{Fastness Testing}

The fastness properties were determined according to the international standards of textile testing. The specific tests used were ISO-105-X10, BS1006:1990 (Assessment of migration of textile color into polyvinyl chloride coating), ENISO-14184-1:1998 (Formaldehyde release), AATCC-08 (color fastness to crocking) [12-14].

\section{Results \& Discussion}

The pigment printing was performed with 5\% Imparon red $\mathrm{KB}$ pigment in the laboratory with simple screen 
printing method. The effect of two different binders, acrylate based and butadiene based on crocking, PVC migration and formaldehyde release were investigated.

\subsection{Effect of Binder Concentration on K/S Values}

As the binder concentration increases, the K/S values of both printed fabric treated with acrylate and butadiene based binder increases however the $\mathrm{K} / \mathrm{S}$ values recorded for fabric treated with butadiene was higher than the fabric treated with acrylate based binder (Figure 2). The maximum values of K/S, 13.46, attained at a butadiene concentration of $15 \mathrm{~g} / \mathrm{l}$. Pigment particles are molecular aggregates which does not contain any groups capable of reacting with fibers or substrate. The size and lack of functionality required that pigment could be bonded to the fibers by the use of binder, which is a high molecular weight film forming material. The binder is the only linkage between pigment and the fabric and therefore plays crucial part in determining the color strength of the finished fabric.

\subsection{Effect of Curing Time on K/S Values}

The K/S values decreases with increase in curing time of the printed fabric treated with both butadiene and acrylate based binder. The maximum K/S values, 13.72 have been recorded after 2 minutes for butadiene based binder (Figure 3). The curing time slightly affects K/S values; the binder which encloses the pigment molecules, forms a film under curing conditions. The improved adhesion of the film to the substrate could be achieved by crosslinking. The reaction should be activated in dry hot air.

\subsection{Effect of Binder Concentration on Formaldehyde Release}

The formaldehyde release decreased for both type of

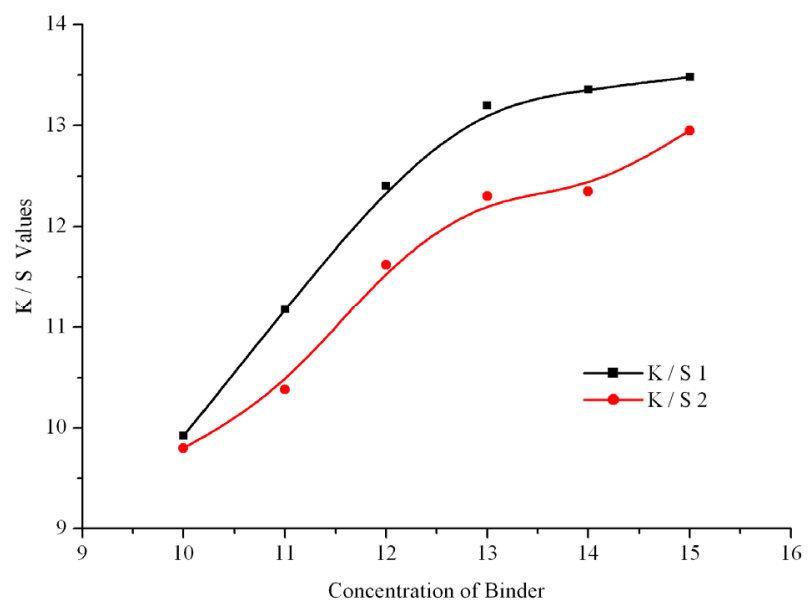

K/S 1: Butadiene binder; K/S 2: Acrylate binder.

Figure 2. Binder concentration v/s KS value. binders with increase in binder concentration. Butadiene showed minimum values of formaldehyde content i-e $0.87 \mathrm{ppm}$ at a concentration ratio of $15 \mathrm{~g} / \mathrm{l}$. It may be due to the interaction of the formaldehyde molecules with the binders and also the butadiene based binders have more reactive sites as compared to the acrylate based binder and probability of crosslinking with formaldehyde molecule will be more in case of butadiene based binder as compared to the acrylate based binder (Figure 4).

\subsection{Effect of Binder Concentration on Crocking Fastness}

As the butadiene concentration increases the wet and dry crocking fastness for both butadiene and acrylate based binder also increases. At a binder concentration of 15\% the butadiene binder shows optimum results of crocking i.e. 5 both for wet and dry crocking (Table 1).

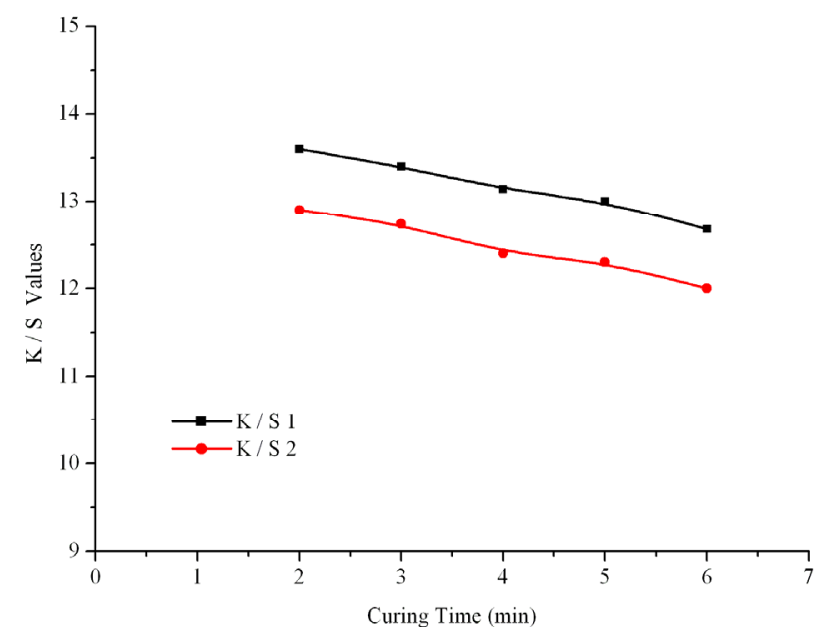

Binder 1: Butadiene binder; Binder 2: Acrylate binder.

Figure 3. Curing time v/s KS value.

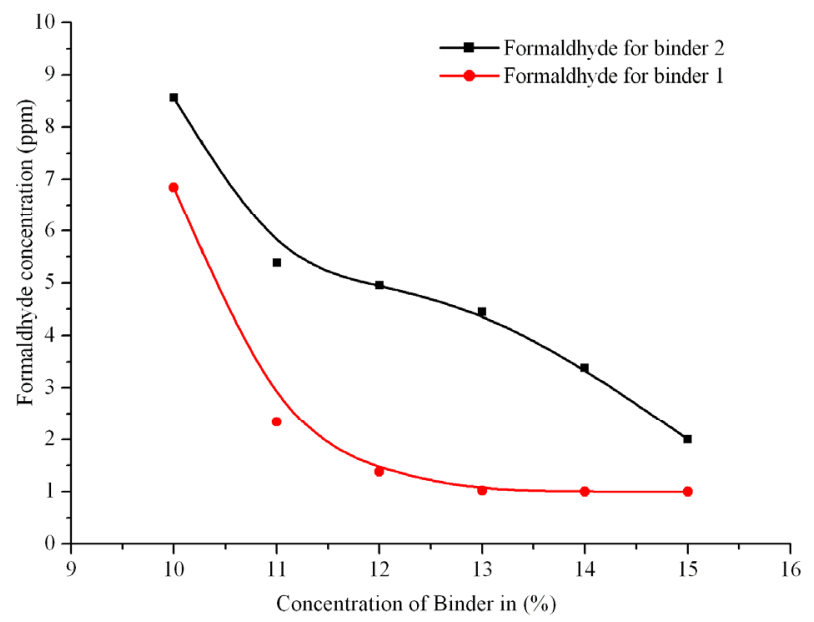

Binder 1: Butadiene binder; Binder 2: Acrylate binder.

Figure 4. Binder concentration v/s formaldehyde content. 
Factors that affect crocking are the elasticity of the binder in conjunction with the pigment film placement on the fabric and the quantity of the binder in the mixture. Also important is the adhesion of the pigment to the fabric with uniformity of the pigment within the color matrix. Factors which affect wet crocking are the toughness of the binder film as well as the water resistance of the binder. Butadiene improves the crock fastness and also softened the hand of the fabric. Butadiene is unique in the fact that it contains two reactive double bond, one polymerized there remain one unsaturated double bond. Thus double bonds give butadiene its elastic properties which make it soft and provide good dimensional recovery. Acrylates are thermoplastic polymers which mean they do not have good dimensional recovery. This results in reduced abrasion resistance. All acrylates binders require copolymerization with functional monomers to achieve acceptable fastness properties.

\subsection{Effect of Binder Concentration on PVC Migration}

Tables 2 and $\mathbf{3}$ show the Effect of Binder Concentration on PVC migration. At a concentration of binder i.e. 13\% the K/S indicates that PVC migration decreases after 6 minutes. It is found to be minimum for both types of binder. The minimum values of PVC migration could be achieved for butadiene after 6 minutes at K/S values of 0.32. It may be due to the cross linking properties of formaldehyde which resist the PVC migration.

\subsection{Binder Toxicity}

A very large number of workers in the plastics and textile industry are exposed to acrylic and butadiene based polymers. The widespread use of these polymers in industry and in certain laboratories raises questions pertinent to their toxicological properties and their short- and long-term health effects on persons exposed to them.

Butadiene is listed as a potential carcinogen by the International Agency for Research on Cancer (IARC), among others. It has been shown to cause cancer in laboratory. Butadiene Epidemiology studies have linked employment in two different chemical operations each with a Different type of cancer. The factors causing these excess cancers have not been determined because the workers were also exposed to other chemicals. Butadiene has caused birth defects and also injury to reproductive organs [15].

Generally, the systemic toxic effects of the lower molecular weight acrylic based polymers are manifested by an immediate increase in respiration followed by a decrease in 15 - 40 min. A prompt fall in blood pressure also occurs, followed by recovery within 4 - 5 min. As the person approaches to death, respiration becomes
Table 1. Colorfastness to crocking (AATCC-08).

\begin{tabular}{ccccc}
\hline \multirow{2}{*}{$\%$ of Binder } & \multicolumn{2}{c}{ Butadiene } & \multicolumn{2}{c}{ Acrylate } \\
\cline { 2 - 5 } & Dry & Wet & Dry & Wet \\
\hline $10 \%$ & 4 & 3 & $3-4$ & 2 \\
$11 \%$ & 4 & $3-4$ & $3-4$ & $2-3$ \\
$12 \%$ & 4 & 4 & 4 & $2-3$ \\
$13 \%$ & $4-5$ & 4 & $4-5$ & 3 \\
$14 \%$ & $4-5$ & $4-5$ & $4-5$ & $3-4$ \\
$15 \%$ & 5 & 5 & $4-5$ & $3-4$ \\
\hline
\end{tabular}

Table 2. Effect of PVC migration with butadiene binder.

\begin{tabular}{cccccc}
\hline $\begin{array}{c}\text { Binder Concentration/ } \\
\text { Curing time }\end{array}$ & L & a & b & C & K/S \\
\hline 13\% for 4 min & 89.23 & 5.23 & 0.82 & 1.68 & 0.78 \\
$13 \%$ for 5 min & 91.23 & 4.03 & 0.68 & 1.42 & 0.34 \\
$13 \%$ for 6 min & 91.27 & 4.12 & 0.65 & 1.27 & 0.32 \\
\hline
\end{tabular}

Table 3. Effect of PVC migration with Acrylate Binder.

\begin{tabular}{cccccc}
\hline $\begin{array}{c}\text { Binder Concentration/ } \\
\text { Curing time }\end{array}$ & $\mathbf{L}$ & $\mathbf{a}$ & $\mathbf{b}$ & $\mathbf{c}$ & $\mathbf{K} / \mathbf{S}$ \\
\hline $13 \%$ for 4 min & 88.47 & 6.50 & 1.06 & 2.08 & 0.86 \\
$13 \%$ for 5 min & 89.80 & 5.43 & 0.88 & 1.63 & 0.67 \\
$13 \%$ for 6 min & 90.05 & 5.23 & 0.72 & 1.34 & 0.48 \\
\hline
\end{tabular}

labored and irregular, lacrimation may occur, defecation and urination increase, and finally reflex activity ceases and the person die in coma [16].

\section{Conclusions}

The present studies have been made to evaluate the crocking fastness properties, PVC migration and formaldehyde release of pigment printed fabric by the use of acrylate based binder and butadiene based binder. By the above investigation the following conclusions have been drawn.

Butadiene showed good results of PVC migration, crocking fastness and formaldehyde release as compared to the acryalate based binder. Butadiene showed minimum value of formaldehyde content of $0.87 \mathrm{ppm}$ at a concentration of $15 \%$. The K/S values of butadiene binder found to be maximum after 2 minutes i.e. 13.72, at a binder concentration of $15 \%$; the butadiene showed optimum results of crocking i.e. 5 both for wet and dry rubbing. An increase in the binder concentration will results in lowering the formaldehyde release for both type of binders, however this release is minimum in case of butadiene binder. It has also been observed that as the curing time increased the value of K/S decreased for both type 
of binders.

\section{REFERENCES}

[1] M. M. Molla, "Synthesis of Polyurethane Acrylate Oligomers as Aqueous UV-Curable Binder for Inks Jet in Textile Printing and Pigment Dyeing," Dyes and Pigments, Vol. 74, No. 10, 2007, pp. 371-379. doi:10.1016/j.dyepig.2006.02.021

[2] K. Oza and K. Shah, "Aqueous System for Pigment Printing,” Textile Dyers and Printers, Vol. 21, No. 11, 1988, pp. 21-25.

[3] A. Poehlmann, "Pigment Printing System,” Textile Industries Dyegist, Vol. 11, No. 10, 1992, pp. 4-9.

[4] R. M. Christie, “The Chemistry of Color Application,” 1st Edition, Blackwell Science, England, 2000.

[5] W. C. Miles, "Textile Printing," 2nd Edition, Society of Dyers and Colorist, Bradford England, 2004.

[6] G. Hammonds, "Pigment Printing Handbook," 1st Edition, American Association of Textile Chemist and Colorists, Research Triangle Park, N.C, 1995.

[7] V. A. Shenai, “Technology of Textile Printing,” 2nd Edition, Sevak Publisher, Mumbai, 1990.

[8] Mansoor Iqbal, "Effect of Cross Linking in Textile Pig- ment Printing and Enhancement of Fastness Properties," Journal of Chemical Society of Pakistan, Vol. 31, No. 1, 2009, pp. 145-150.

[9] A. Johnson,” The Theory of Coloration of Textiles,” 2nd Edition, Dyers Company Publications Trust, Bradford England, 1989.

[10] W. C. Miles, “Textile Printing,” 2nd Edition, Society of Dyers and Colorist, Bradford England, 2004.

[11] V. A. Shenai, “Chemistry of Textile Auxiliaries," 2nd Edition, Sevak Publisher, Mumbai, 2002.

[12] AATCC Test Method-8, Color Fastness to Crocking, 2005.

[13] ISO-105-X10, BS 1006, “Assessment of Migration of Textile Color into Polyvinyl Chloride Coating,” 1990.

[14] EN-ISO14184-1, “Textiles, Determination of Formaldehyde, Part 1, Free and Hydrolyzed Formaldehyde Water Extraction Method,” 1998.

[15] American Chemistry Council, "Butadiene Product Stewardship Guidance Manual,” 2010. http://www.dow.com/productsafety/pdfs/butadiene_guide .pdf

[16] J. Autian, "Structure-Toxicity Relationships of Acrylic Monomers," Environmental Health Perspectives, Vol. 11, No. 2, 1975, pp. 141-152. doi:10.1289/ehp.7511141 